\title{
BIBECHANA
}

A Multidisciplinary Journal of Science, Technology and Mathematics

ISSN 2091-0762 (online)

Journal homepage: http://nepjol.info/index.php/BIBECHANA

\section{A non-destructive compositional analysis of thin surface films formed on W-XTa alloys by angle resolved $X$-ray photoelectron spectroscopy}

\author{
Jagadeesh Bhattarai \\ Central Department of Chemistry, Tribhuvan University, Kathmandu, Nepal. \\ e-mail:bhattarai_05@yahoo.com \\ Article history: Received 22 May, 2011; Accepted 11 June, 2011
}

\begin{abstract}
Synergistic effect of the simultaneous additions of tungsten and tantalum in the extremely high corrosion resistance properties of the spontaneously passivated sputter-deposited W-xTa alloys was investigated using a non-destructive angle resolved $\mathrm{X}$-ray photoelectron spectroscopy (angle resolved XPS) techniques in this study. In-depth surface analyses of the thin passive films formed on the spontaneously passivated amorphous/nanocrystalline W-xTA alloys using angle resolved XPS analyses revealed that the high corrosion resistance of the alloys is mostly due to the formation of homogeneous passive double oxyhydroxide films consisting of $\mathrm{W}^{\text {ox }}$ and $\mathrm{Ta}^{4+}$ cations with a small concentration gradients in-depth particularly after immersion between 20 $168 \mathrm{~h}$ in $12 \mathrm{M} \mathrm{HCl}$ solution open to air at $30^{\circ} \mathrm{C}$. Consequently, tantalum metal acts synergistically with tungsten in enhancing the spontaneous passivity as well as the high corrosion resistance of the sputter-deposited binary $\mathrm{W}-\mathrm{xT}$ a alloys in $12 \mathrm{M} \mathrm{HCl}$ solution.
\end{abstract}

Keywords: Sputter deposition; W-xTa alloys; $12 \mathrm{M} \mathrm{HCl}$; Take-off angle

\section{Introduction}

An Angle Resolved XPS proves as one of the promising in-depth compositional analyses of thin films to investigate chemical compositions, oxidation states, chemical shifts, binding energies and electronic structures of the surface films [1-7]. For this purpose the non-destructive angle resolved XPS technique is widely used by a number of researchers to gain about the in-depth concentration profiles of the passive films. In principle, the in-depth information of the passive film depends on the effective escape depth of the ejected photoelectrons, which increases with an increase in the take-off angle of photoelectrons relative to the surface of the sample specimen [1-8]. Therefore, the surface sensitivity is varied by changing the take-off angle of photoelectrons $(\theta)$ as explain by equation (1). In general, the surface sensitivity is varied by changing the take-off angle of photoelectrons. At a lower take-off angle of photoelectrons, the intensity signals (I) from the sample species located in the exterior part of the surface films are enhanced. Therefore, the apparent compositions of the surface films are changed with the take-off angle of photoelectrons in the angle resolved XPS measurements. 


$$
\mathrm{I}=\mathrm{k} \exp (-\mathrm{z} / \lambda \sin \theta)
$$

Where, $\mathrm{I}$ is the intensity of the ejected photoelectrons, $\mathrm{k}$ is constant, $\mathrm{z}$ is the depth of the surface and $\theta$ is the take-off angle of the ejected photoelectrons.

In recent years, angle resolved XPS (ARXPS) technique is one of the very useful in-depth surface characterization tools for corrosion scientists to study the mechanism of high corrosion resistance of materials during last four decades after a valuable contribution of Kai Siegbahn and his research groups [9]. It allows us to examine the formation of homogeneous or heterogeneous passive surface films formed on the corrosion-resistant alloys [8,10-19].

Tungsten and tantalum are effective elements in enhancing the corrosion resistance of alloys in aggressive environments. Several surface studies have been carried out for a better understanding of the role of tungsten in the corrosion resistance properties of the sputter-deposited binary $[12,14-16,18,20-37]$ and ternary $[19,38-43]$ tungsten-based alloys in aggressive environments. It is reported that the addition of tungsten to amorphous $\mathrm{Fe}-\mathrm{P}-\mathrm{C}$ alloys with and without chromium [44,45] and to the amorphous Ni-P alloys [46] is effective in improving the corrosion resistance in aggressive hydrochloric acid solutions.

Similarly, tantalum is widely known for its superior corrosion resistance in aggressive acidic media. Amorphous nickel-base alloys containing certain amounts of tantalum exhibit very high corrosion resistance in boiling concentrated acids $[47,48]$. Lee et al. reported a beneficial effect of tantalum to improve the corrosion resistance of nickel base alloys in $12 \mathrm{M} \mathrm{HCl}[48,49]$. A series of sputter-deposited binary $[11,13,20,50,51]$ and ternary [52,53] tantalum-containing alloys showed high corrosion resistance due to spontaneous passivation in aggressive media. In particular, the sputter-deposited W-xTa alloys were passivated spontaneously and showed significantly high corrosion resistance in $12 \mathrm{M} \mathrm{HCl}$ solution. Their corrosion rates were found about two orders of magnitude lower than that of sputter-deposited tungsten and even lower than that of tantalum. The conventional XPS analyses confirmed that the formation of the spontaneously passivated films formed on the alloys composed of double oxyhydroxide of tungsten and tantalum ions was found to be responsible for their higher corrosion resistance those of alloying elements of the WxTa alloys in $12 \mathrm{M} \mathrm{HCl}$ solution. In this context, the present work is aimed to clarify the mechanism of the higher corrosion resistance of the sputter-deposited nanocrystalline W-23Ta and $\mathrm{W}-60 \mathrm{Ta}$ alloys than those of tungsten and tantalum in $12 \mathrm{M} \mathrm{HCl}$ solution open to air at $30^{\circ} \mathrm{C}$ using angel resolved XPS techniques.

\section{Materials and Experimental Methods}

The sputter-deposited W-23Ta and W-60Ta alloys were characterized as nanocrystalline single-phase solid solution having an apparent grain size of 10-20 nm from XRD patterns using Scherrer's formula [54]. The compositions of the alloys hereafter are all denoted in atomic percentage (at\%). Prior to the corrosion tests and angle resolved XPS analyses, the sputterdeposited W-xTa alloy specimens were mechanically polished with a silicon carbide paper up to grit number 1500 in cyclohexane, degreased by acetone and dried in air. The average corrosion rate of the alloys was estimated from weight loss after immersion for $168 \mathrm{~h}$ in $12 \mathrm{M} \mathrm{HCl}$ solution open to air at $30^{\circ} \mathrm{C}$.

The composition of the spontaneously passivated films formed on the $\mathrm{W}-\mathrm{xTa}$ alloys was analyzed by angle-resolved XPS. Before and after immersion in $12 \mathrm{M} \mathrm{HCl}$ solution, XPS spectra were measured by a Shimadzu ESCA-850 photoelectron spectrometer with $\mathrm{Mg} \mathrm{K}_{\square}$ (hv $=1253.6$ $\mathrm{eV}$ ) radiation for surface analyses including the in-depth surface compositions of the alloys. XPS spectra for both the nanocrystalline $\mathrm{W}-23 \mathrm{Ta}$ and $\mathrm{W}-60 \mathrm{Ta}$ alloys over a wide binding energy region (that is, $0-1000 \mathrm{eV}$ ) exhibited peaks of tungsten, tantalum, carbon, oxygen and chlorine. 
The most intense peaks of the $\mathrm{W} 4 \mathrm{f}, \mathrm{Ta} 4 \mathrm{f}, \mathrm{C} 1 \mathrm{~s}, \mathrm{O} 1 \mathrm{~s}$ and $\mathrm{Cl} 2 \mathrm{p}$ electrons were measured in the binding energy range of $20 \mathrm{eV}$ for all spectra except for $\mathrm{W} 4 \mathrm{f}$ and $\mathrm{Ta} 4 \mathrm{f}$ electrons. The most intense peaks of the $\mathrm{W} 4 \mathrm{f}$ and Ta $4 \mathrm{f}$ spectra are located very close to each other and they are partially overlapped as discussed elsewhere $[20,55]$. Hence, the $W 4 f$ and Ta $4 f$ electrons were measured in the binding energy range of $30 \mathrm{eV}[20,55]$. The peak shift (chemical shift) caused by the charging effect was corrected using the difference the measured binding energy of the contaminant $\mathrm{C}$ 1s peak and assumed value of $285.0 \mathrm{eV}$. For the alloy specimens after immersed in $12 \mathrm{M} \mathrm{HCl}$ solution, a very weak $\mathrm{Cl} 2 \mathrm{p}$ spectrum was detected at about $199.0 \mathrm{eV}$. However, the concentration of the chloride ion was not considered for the quantitative analyses of the surface films in this study because the intensity of the chloride ion is very low for quantitative analyses. The $\mathrm{O} 1 \mathrm{~s}$ spectrum was composed of two peaks; the lower binding energy peak at $530.4 \mathrm{eV}$ was assigned to OM oxygen, and the higher binding energy peak at $532.3 \mathrm{eV}$ was assigned to $\mathrm{OH}$ oxygen [56]. The spectra from the $\mathrm{W}-\mathrm{xTa}$ alloys constituents indicated the presence of the oxidized and metallic species; the former comes from the surface film and the latter from the underlying alloy surface. The measured spectrum of $W 4 f$ electron was separated into $W^{\text {ox }} 4 f$ and $W^{m} 4 f$ and the measured spectrum of Ta $4 f$ electron was separated into $\mathrm{Ta}^{4+} 4 \mathrm{f}$ and $\mathrm{Ta}^{\mathrm{m}} 4 \mathrm{f}$ for the sputter-deposited $W-x T a$ alloys. Furthermore, the $W^{m} 4 f$ spectrum was consisted of $W^{4+} 4 f, W^{5+}$ $4 f$ and $W^{6+} 4 f$ spectra. The integrated intensities of the $W^{0} 4 f, W^{4+} 4 f, W^{5+} 4 f, W^{6+} 4 f, T a^{m} 4 f$, and $\mathrm{Ta}^{4+} 4 \mathrm{f}$ were obtained by the same method as those described elsewhere $[20,55]$.

After the integrated intensities of these all spectra observed from the surfaces of the sputter-deposited $\mathrm{W}-\mathrm{xTi}$ alloys were obtained, the compositions and thickness of the passive films and the compositions of the underlying alloy surfaces were quantitatively determined using three layers model proposed by Asami et al. $[56,57]$. The diagrammatic sketch of the three layers model is shown in Fig. 1. For angle-resolved XPS, the angle between the alloy specimen surface and the direction of photoelectron to the detector (take-off angle of photoelectrons) was changed by using tilted-specimen holders at $30^{\circ}, 45^{\circ}, 60^{\circ}$ and $90^{\circ}$ as discussed elsewhere [55]. The photo-ionization cross-section of the $\mathrm{W} 4 \mathrm{f}$ and $\mathrm{T}$ a $4 \mathrm{f}$ electrons relative to the $\mathrm{O}$ 1s electrons used were 2.97 [58] and 2.617 [59], respectively.

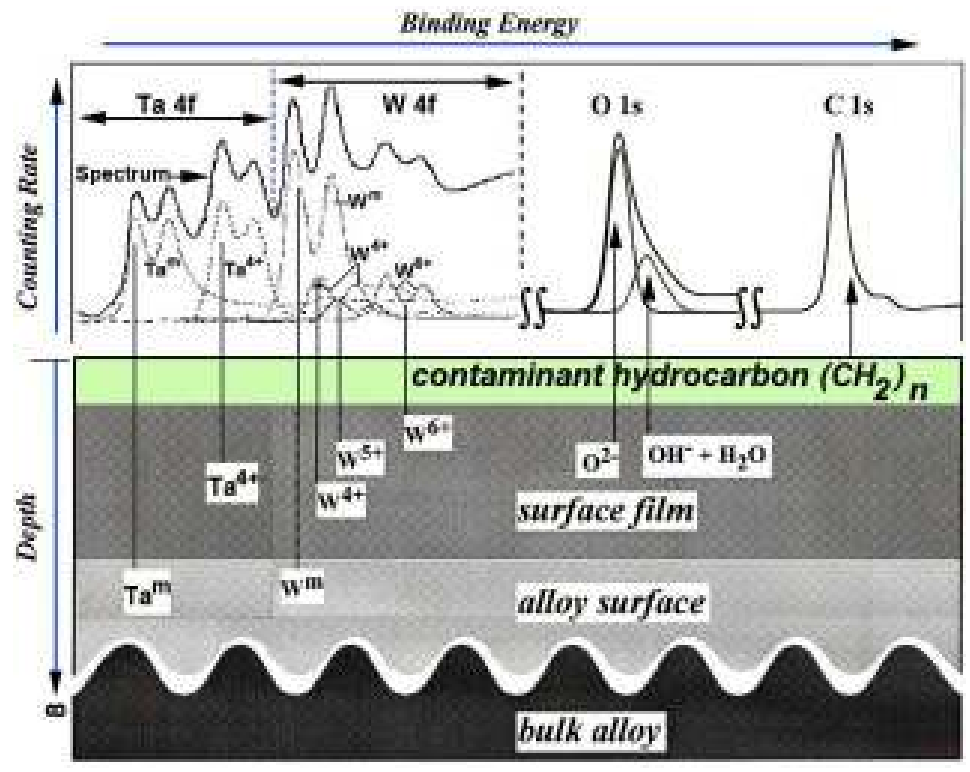

Fig. 1: A diagrammatic sketch of the three layers model for the quantitative XPS analyses of the surface films formed on the sputter-deposited W-xTa alloys. 
Jagadeesh Bhattarai / BIBECHANA 8 (2012) 8-16 : BMHSS, p. 11

\section{Results and Discussion}

It was reported that the synergistic effect of tungsten and tantalum in forming the double oxyhydroxide was responsible for the higher corrosion resistance of the sputter-deposited amorphous/nanocrystalline $\mathrm{W}-\mathrm{xTa}$ alloys than those of the alloy-constituting elements in $12 \mathrm{M}$ $\mathrm{HCl}$ solution open to air at $30^{\circ} \mathrm{C}$ from the conventional XPS analyses. However, the experimental results of the angle resolved XPS measurements are presented here to clarify the mechanism of showing the higher corrosion resistance behavior of the sputter-deposited binary $\mathrm{W}-\mathrm{xTa}$ alloys than those of alloy-constituting elements in $12 \mathrm{M} \mathrm{HCl}$. Because, the in-depth surface analyses of the spontaneously passivated double oxyhydroxide films formed on the W-xTa alloys using angle resolved XPS measurements give very important information for a better understanding of the effects of tungsten and tantalum additions in the corrosion-resistant behavior of the alloys. An information about in-depth composition changes of the spontaneously passivated films formed on the W-23Ta and W-60Ta alloys were obtained by a non-destructive depth profiling technique of the angle resolved XPS to know whether the spontaneously passivated films formed on the alloys are homogeneous or not.

The spectra from the $\mathrm{W}-\mathrm{xTa}$ alloys constituents indicated the presence of the oxidized and metallic species; the former comes from the surface film and the latter from the underlying alloy surface. The measured spectrum of $\mathrm{Ta} 4 \mathrm{f}$ electrons was separated into $\mathrm{Ta}^{4+} 4 \mathrm{f}$ and $\mathrm{Ta}^{\mathrm{m}} 4 \mathrm{f}$ spectra as shown in Fig. 1 and the measured spectrum of $W 4 f$ electrons was separated into $\mathrm{W}^{\mathrm{m}}$ $4 \mathrm{f}$ and $\mathrm{W}^{\mathrm{ox}} 4 \mathrm{f}$ as shown in Fig. 1 for the sputter-deposited W-45Ta alloy in the given conditions [55]. The $\mathrm{Ta}^{4+} 4 \mathrm{f}$ and $\mathrm{Ta}^{\mathrm{m}} 4 \mathrm{f}$ spectra were consisted of lower and higher binding energy peaks corresponding to $\mathrm{Ta}^{4+} 4 \mathrm{f}_{7 / 2}$ and $\mathrm{Ta}^{4+} 4 \mathrm{f}_{5 / 2}$ electrons, and $\mathrm{Ta}^{\mathrm{m}} 4 \mathrm{f}_{7 / 2}$ and $\mathrm{Ta}^{\mathrm{m}} 4 \mathrm{f}_{5 / 2}$ electrons, respectively, as shown in Fig. 1. Furthermore, the $W^{m} 4 f$ spectrum was consisted of lower and higher binding energy peaks corresponding to $W^{m} 4 f_{7 / 2}$ and $W^{m} 4 f_{5 / 2}$ electrons. Similarly, the $W^{o x}$ $4 \mathrm{f}$ spectrum was also composed of three doublets of the overlapped spectra of three oxidized species, that is, doublets of $W^{4+} 4 f_{7 / 2}$ and $W^{4+} 4 f_{5 / 2} ; W^{5+} 4 f_{7 / 2}$ and $W^{5+} 4 f_{5 / 2}$; and $W^{6+} 4 f_{7 / 2}$ and $W^{6+}$ $4 f_{5 / 2}$ electrons as shown in Fig. 1.

The quantitative result of the in-depth compositional change in the surface films formed on the sputter-deposited W-xTa alloys using angle resolved XPS analysis is shown in Fig. 2. Figures 2 (a) and 2 (b) show the changes in apparent cationic fractions in the spontaneously passivated films and the apparent atomic fractions in the underlying alloy surfaces of the W-23Ta and W-60Ta alloys, respectively, after immersion for different periods of time in $12 \mathrm{M} \mathrm{HCl}$ solution open to air at $30^{\circ} \mathrm{C}$, respectively, as a function of take-off angle of photoelectrons. It is clearly raveled that tantalum is concentrated in the spontaneously passivated films, while tantalum is deficient in the underlying alloy surfaces. The concentration of tantalum ion is slightly higher in the exterior part (at take-off angle of $30^{\circ}$ ) of the passive films formed on both the sputter-deposited W-23Ta and W-60Ta alloys by immersion for 20 hours or more in $12 \mathrm{M} \mathrm{HCl}$, while there is also small concentration gradient of cations in-depth of the underlying alloys. On the other hand, the concentration of tungsten is slightly higher in the exterior part (at take-off angle of $90^{\circ}$ ) of the underlying alloy surfaces and the tungsten concentration decreases with take-off angles after immersion in $12 \mathrm{M} \mathrm{HCl}$ solution. 


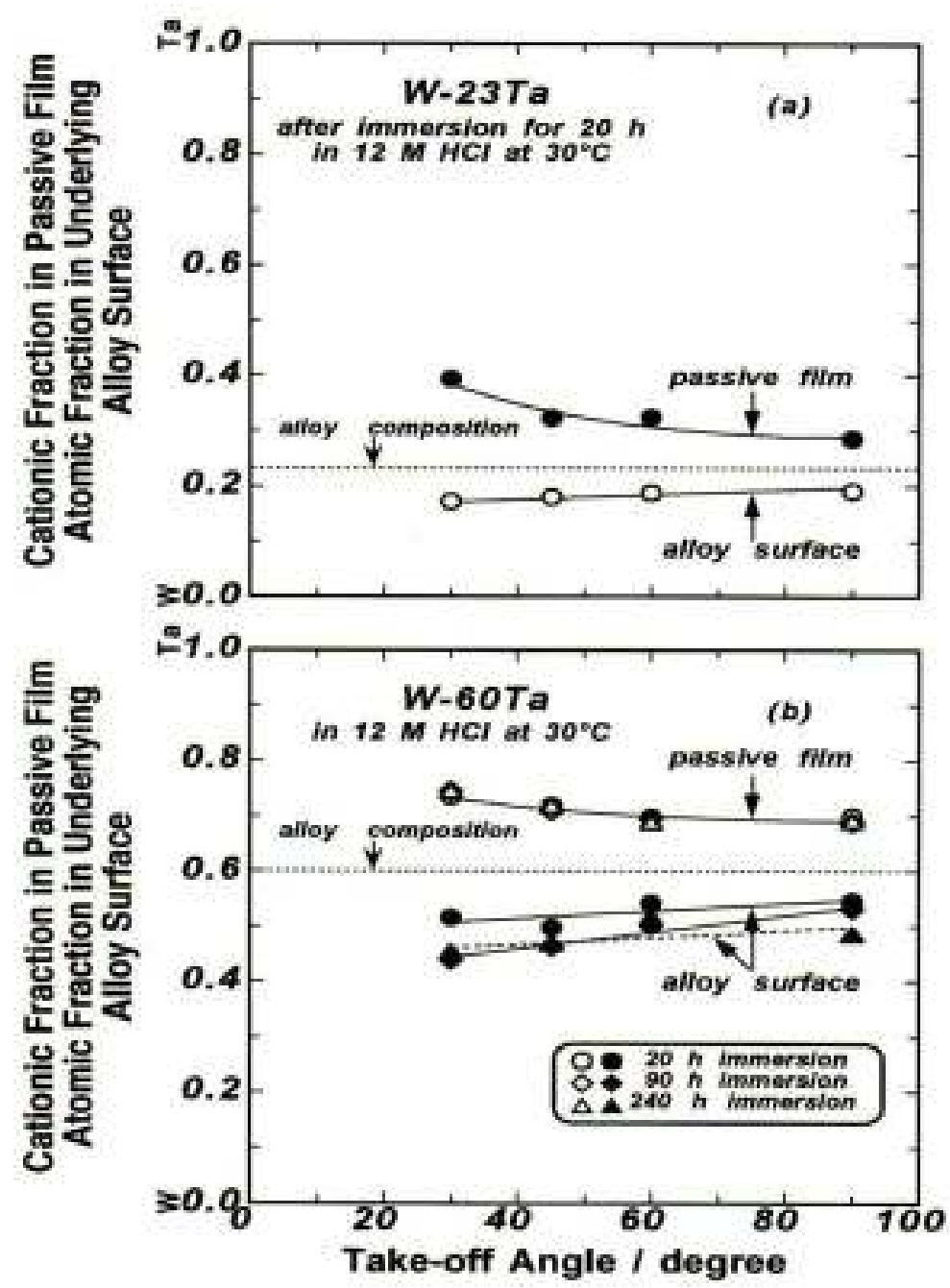

Fig. 2: Changes in the apparent cationic fractions in the passive film and the atomic fractions in the underlying alloy surface for the (a) W-23Ta and (b) W-60Ta alloy as a function of take-off angle of photoelectrons.

For a better understanding of the role of tungsten ions in the passive films formed on the alloys, the changes in the ratios of $\mathrm{W}^{4+}, \mathrm{W}^{5+}$ and $\mathrm{W}^{6+}$ ions in the surface films were determined quantitatively. Figure 3 shows the concentration ratios of $\mathrm{W}^{4+}, \mathrm{W}^{5+}$ and $\mathrm{W}^{6+}$ ions to the total tungsten ions in the spontaneously passivated films formed on the $\mathrm{W}-23 \mathrm{Ta}$ and $\mathrm{W}-60 \mathrm{Ta}$ alloys after immersion for $20 \mathrm{~h}$ in $12 \mathrm{M} \mathrm{HCl}$ solution open to air at $30^{\circ} \mathrm{C}$, as a function of take-off angle of photoelectrons. After immersion for $20 \mathrm{~h}$ in $12 \mathrm{M} \mathrm{HCl}$ solution, the ratio of $\mathrm{W}^{6+}$ ions in the passive films formed on both the $\mathrm{W}-23 \mathrm{Ta}$ and $\mathrm{W}-60 \mathrm{Ta}$ alloys are significantly higher than those of $\mathrm{W}^{4+}$ and $\mathrm{W}^{5+}$ ions in the spontaneously passivated films. $\mathrm{W}^{6+}$ ion decreases with increasing take-off angle of photoelectrons, while $\mathrm{W}^{4+}$ ion increases with take-off angles. The ratio of $\mathrm{W}^{5+}$ ion remains almost constant with take-off angle of photoelectrons. Accordingly, $\mathrm{W}^{4+}$ ion is particularly concentrated in the interior (at take-off angle of $90^{\circ}$ ) of the spontaneously passivated film formed on the sputter-deposited $\mathrm{W}-\mathrm{xTa}$ alloys, while the concentration of $\mathrm{W}^{6+}$ ion is higher in 
the exterior (at take-off angles of 30 to $60^{\circ}$ ) of the spontaneously passivated films. It is generally known that air exposure of the specimen during transfer from the electrolyte to the XPS analyzing chamber give rise to oxidation of $\mathrm{W}^{4+}$ to $\mathrm{W}^{6+}$ ion. Accordingly the relative ratio of $\mathrm{W}^{6+}$ ion is higher in the exterior of the surface films and decreases with the depth of the passive film.

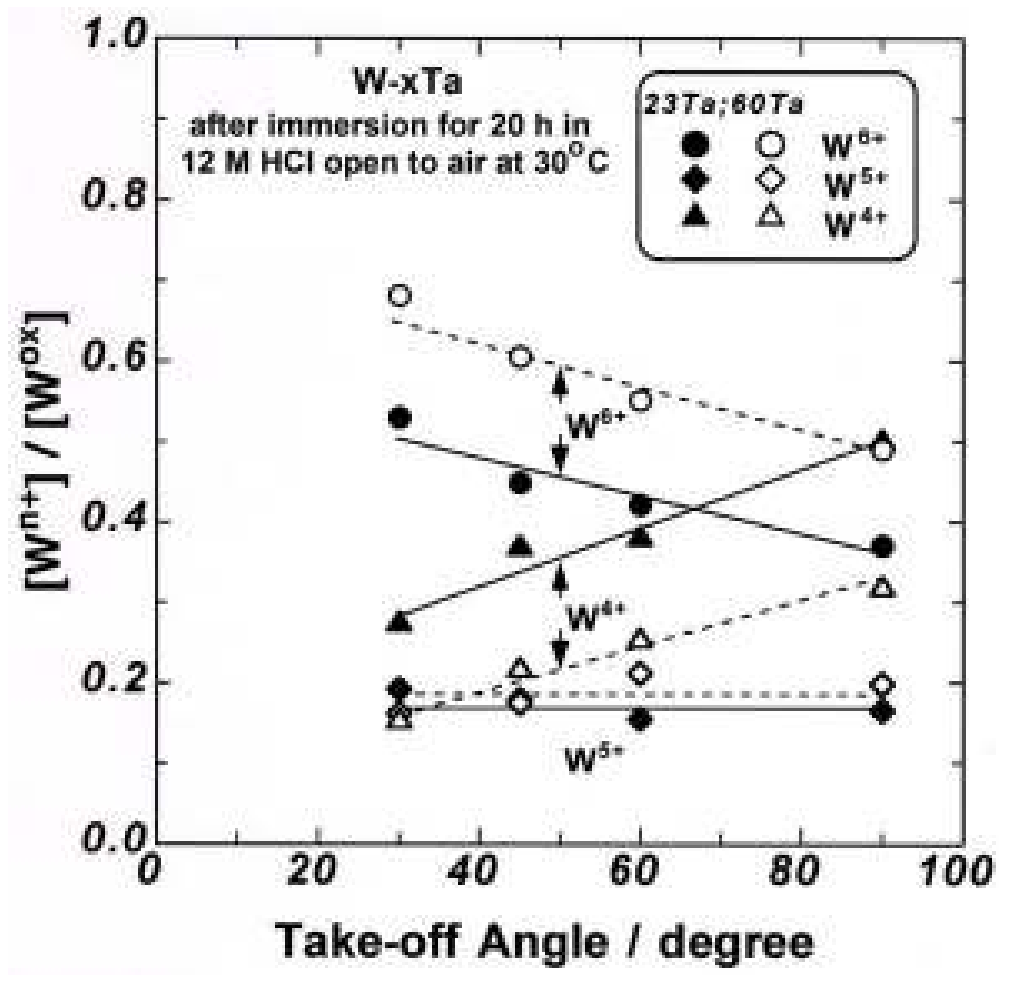

Fig. 3: Changes in the apparent cationic fractions in the passive film and the atomic fractions in the underlying alloy surface for the (a) W-23Ta and (b) W-60Ta alloys, as a function of take-off angle of photoelectrons.

In general, one of the characteristic of the thin passive films is the concentration of oxygen species in the spontaneously passivated films formed on the corrosion-resistant alloys. Figure 4 shows the changes in the ratios of $\left[\mathrm{O}^{2-}\right] /[$ cations] and $[\mathrm{OH}] /[$ cations] in the spontaneously passivated films formed on the sputter-deposited amorphous $\mathrm{W}-23 \mathrm{Ta}$ and $\mathrm{W}-60 \mathrm{Ta}$ alloys after immersion for $20 \mathrm{~h}$ in $12 \mathrm{M} \mathrm{HCl}$ solution open to air at $30^{\circ} \mathrm{C}$, as a function of take-off angle of photoelectrons. The ratios of $\left[\mathrm{O}^{2-}\right] /[$ cations] slightly increase with the take-off angles and the ratios of $[\mathrm{OH}] /[$ cations] significantly decrease with take-off angles in the films formed on the $\mathrm{W}-\mathrm{xTa}$ alloys. Consequently, the interior part of the passive films formed on the sputter-deposited $\mathrm{W}-\mathrm{xT}$ a alloys is rather dry and well developed by $\mathrm{M}-\mathrm{O}-\mathrm{M}$ bridging, while the exterior part of the passive films formed on the alloys is slightly wet with $\mathrm{OH}^{-}$ion and $\mathrm{H}_{2} \mathrm{O}$. 


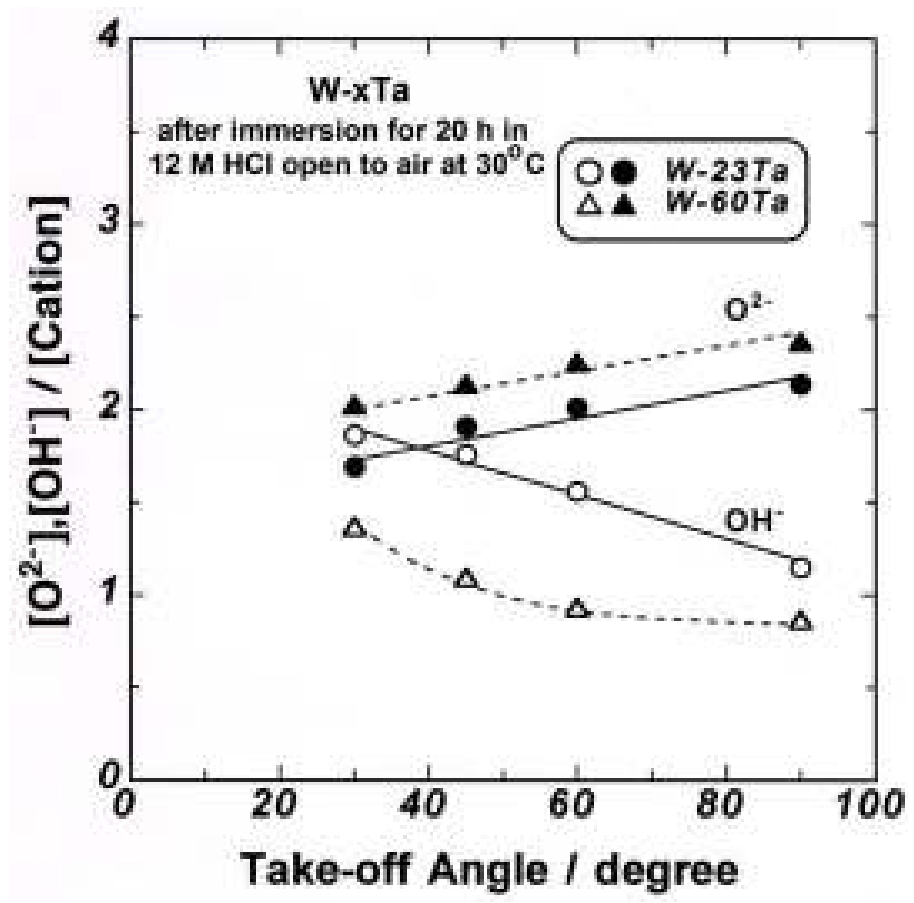

Fig. 4: Changes in the ratios of $\left[\mathrm{O}^{2-}\right] /\left[\right.$ cations and $\left[\mathrm{OH}^{-}\right] /[$cations] in the surface films formed on the W-23Ta and W-60Ta alloys in the given conditions, as a function of take-off angle of photoelectrons.

\section{Conclusion}

The mechanism of the synergistic effect of tungsten and tantalum metals enhancing the higher corrosion resistance of the sputter-deposited nanocrystalline W-23Ta and W-60Ta alloys than those of alloy-constituting elements has been studied using angle resolved XPS measurements in $12 \mathrm{M} \mathrm{HCl}$ solution open to air at $30^{\circ} \mathrm{C}$. The following conclusions are drawn:

1. The angle-resolved XPS measurement revealed that all cations of the binary W-xTa alloys are distributed homogeneously in the spontaneously passivated films formed on the alloys. The higher corrosion resistance of the alloys than those of the alloying elements is mostly due to the formation of the homogeneous passive films composed of both $\mathrm{W}^{4+}$ and $\mathrm{Ti}^{4+}$ ions with a small concentration gradient in-depth.

2. The $\mathrm{W}^{4+}$ ion is particularly concentrated in the interior of the spontaneously passivated films formed on both the W-23Ta and W-60Ta alloys, while the concentration of $\mathrm{W}^{6+}$ ion is higher in the exterior of the passive films.

3. The interior part of the passive films formed on the W-xTa alloys is rather dry and well developed by $\mathrm{M}-\mathrm{O}-\mathrm{M}$ bridging, while the exterior part of the passive films formed on the alloys is slightly wet with $\mathrm{OH}^{-}$ion and bound $\mathrm{H}_{2} \mathrm{O}$ molecule.

\section{Acknowledgements}

The author is very thankful to Professors Emeritus; Dr. Koji Hashimoto and Dr. K. Asami of Tohoku University, Sendai, Japan for their kind permission to use the XPS machine. 
Jagadeesh Bhattarai / BIBECHANA 8 (2012) 8-16 : BMHSS, p. 15

\section{References}

[1] L. A. Harris, Surf. Sci. 15 (1969) 77.

[2] W. A. Fraser, J. V. Florio, W. N. Delgass and W. D. Robertson, Surf. Sci. 36 (1973) 661.

[3] C. S. Fadley, J. Electron Spectros. Relat. Phenom. 5 (1974) 725.

[4] C. S. Fadley and R. J. Baird, J. Electron Spectros. Relat. Phenom. 5 (1974) 93.

[5] R. J. Baird and C. S. Fadley, J. Electron Spectros. Relat. Phenom. 11 (1974) 39.

[6] M. Pijolat and G. Hollinger, Surf. Sci. 105 (1981) 114.

[7] S. Tougaard and A. Ignatiev, Surf. Sci. 129 (1983) 355.

[8] E. Akiyama, A. Kawashima, K. Asami, K. and K. Hashimoto, Corros. Sci. 38 (1996) 1127.

[9] K. Siegbhahn, C. Nordling, A. Fahlman, R. Nordberg, K. Hamrin, J. Hedman, G. Johnssaon, T. Bergmark, S. E. Karlsson, I. Lindgren and B. Lindberg, ESSCA-Atomic, Molecular and Solid State Studied by Means of Electron Spectroscopy, Almquist and Wiksells, Uppsal, Sweden (1967).

[10] K. Asami, M. S. De Sa and V. Ashworth, Boshoku Gijustsu 36 (1987) 621.

[11] P. Y. Park, E. Akiyama, A. Kawashima, K. Asami and K. Hashimoto, Corros. Sci. 38 (1996) 398.

[12] J. Bhattarai, E. Akiyama, A. Kawashima, K. Asami and K. Hashimoto, Corros. Sci. 37 (1995) 2071.

[13] X. Y. Li, E. Akiyama, H. Habazaki, A. Kawashima, K. Asami and K. Hashimoto, Corros. Sci. 40 (1998) 1587.

[14] J. Bhattarai, E. Akiyama, H. Habazaki, A. Kawashima, K. Asami and K. Hashimoto, Corros. Sci. 39 (1997) 353.

[15] J. Bhattarai, E. Akiyama, H. Habazaki, A. Kawashima, K. Asami and K. Hashimoto, Corros. Sci. 40 (1998) 19.

[16] J. Bhattarai, E. Akiyama, H. Habazaki, A. Kawashima, K. Asami and K. Hashimoto, Corros. Sci. 40 (1998) 155.

[17] P. Marcus, Electrochim. Acta 1-2 (1998) 109.

[18] J. Bhattarai, J. Nepal Chem. Sci. 19 (2000) 1.

[19] J. Bhattarai, Trans. Mater. Res. Soc. Japan 35(1) (2010)1.

[20] J. Bhattarai, E. Akiyama, H. Habazaki, A. Kawashima, K. Asami and K. Hashimoto, Corros. Sci. 40 (1998) 757.

[21] J. Bhattarai, E. Akiyama, H. Habazaki, A. Kawashima, K. Asami and K. Hashimoto, Corros. Sci. 40 (1998) 1897.

[22] J. Bhattarai and K. Hashimoto, Tribhuvan Univ. J. 21(2) (1998)1.

[23] J. Bhattarai, J. Nepal Chem. Sci. 19 (2000) 32.

[24] J. Bhattarai, J. Nepal Chem. Sci. 20 (2001) 24.

[25] J. Bhattarai, Nepal J. Sci. Technol. 4 (2002) 37.

[26] J. Bhattarai, J. Nepal Chem. Sci. 21 (2006) 19.

[27] J. Bhattarai, S. P. Sah and H. Jha, J. Nepal Chem. Sci. 22 (2007) 7.

[28] A. Sharmah, H. Jha and J. Bhattarai, J. Nepal Chem. Sci. 22 (2007) 17.

[29] H. Jha and J. Bhattarai, J. Alloys Compd. 456 (2008) 474.

[30] S. P. Sah and J. Bhattarai, J Nepal Chem. Soc. 23 (2008/2009), 45.

[31] J. Bhattarai, Tribhuvan Univ. J. 26(1) (2009) 17.

[32] J. Bhattarai, Nepal J. Sci. Technol. 10 (2009) 109.

[33] J. Bhattarai, Scientific World 7 (2009) 24.

[34] P. Shrestha and J. Bhattari, J Nepal Chem. Soc. 25 (2010) 37.

[35] M. Basnet and J. Bhattarai, J. Nepal Chem. Sci. 25 (2010) 53.

[36] J. Bhattarai, J. Nepal Chem. Sci. 26 (2010) 13.

[37] A. Khadka and J. Bhattari, Nepal J. Sci. Technol. 11 (2010) 147.

[38] J. Bhattarai, Scientific World 7 (2009) 24.

[39] P. L. Kharel and J. Bhattarai, J. Nepal Chem. Sci. 24 (2009) 3. 
[40] J. Bhattarai and P. L. Kharel, J. Insti. Sci. Technol. 16 (2009-10) 141.

[41] B. R. Aryal and J. Bhattarai, J. Nepal Chem. Sci. 25 (2010) 75.

[42] R. R. Kumal and J. Bhattarai, J. Nepal Chem. Sci. 25 (2010) 93.

[43] J. Bhattarai, J. Nepal Chem. Sci. 26 (2010) 13.

[44] H. Habazaki, A. Kawashima, A. Asami and K. Hashimoto, J. Electrochem. Soc. 138 (1991) 76.

[45] H. Habazaki, A. Kawashima, A. Asami and K. Hashimoto, Corros. Sci. 33 (1992) 225.

[46] A. Kawashima, K. Asami and K. Hashimoto, Corros. Sci. 24 (1984) 807.

[47] A. Mitsuhihashi, K. Asami, A. Kawashima and K. Hashimoto, Corros. Sci. 27 (1987) 957.

[48] H. J. Lee, E. Akiyama, H. Habazaki, A. Kawashima, K. Asami and K. Hashimoto, Corros. Sci. 39 (1997) 321.

[49] H. J. Lee, E. Akiyama, H. Habazaki, A. Kawashima, K. Asami and K. Hashimoto, Mater. Trans. JIM 37 (1996) 383.

[50] J. H. Kim, E. Akiyama, H. Habazaki, A. Kawashima, K. Asami and K. Hashimoto, Corros. Sci. 36 (1994) 511.

[51] A. A. Moneim, E. Akiyama, H. Habazaki, A. Kawashima, K. Asami and K. Hashimoto, Corros. Sci. 39 (1997) 1965.

[52] A. A. El-Moneim, E. Akiyama, H. Habazaki, A. Kawashima, K. Asami and K. Hashimoto, Corros. Sci. 40 (1998) 1491.

[53] A. A. El-Moneim, K. M. Ismail and M.W. Badway, Electrochimi. Acta 47 (2002) 2460.

[54] B. D. Cullity, in Elements of X-ray Diffraction, $2^{\text {nd }}$ edition, Addison-Wesley Publ. Co. Inc. $p$. 101 (1977).

[55] J. Bhattarai, Ph D Thesis, Tailoring of Corrosion-resistant Tungsten Alloys by Sputtering Method, Tohoku University, Japan (1998).

[56] K. Asami, J. Electron Spectros. Relat. Phenom. 9 (1976) 469.

[57] K. Asami, and K. Hashimoto, Corros. Sci. 17 (1977) 559.

[58] A. Kawashima, K. Asami and K. Hashimoto, Corros. Sci. 24 (1994) 807.

[59] J. H. Kim, H. Yoshioka, H. Habazaki, A. Kawashima, K. Asami and K. Hashimoto, Corros. Sci. 33 (1992) 1507. 